\title{
Analisis Kepuasan Pelanggan Terhadap Pelayanan Astra Motor Yogyakarta Bagian H1 Penjualan Unit Sepeda Motor
}

\author{
AHMAD HUSAIN ABDULLAH ${ }^{1}$, AYUNDYAH KeSUMAWATI \\ 1Program Studi Statistika, Fakultas Matematika dan Ilmu Pengetahuan Alam, \\ Universitas Islam Indonesia
}

\begin{abstract}
ABSTRAK
Kepuasan pelanggan dapat dijadikan sebagai acuan seberapa mampu perusahaan memenuhi nilai harapan pelanggan. Pelanggan yang benar-benar setia terhadap produk barang/jasa akan sangat potensial memperngaruhi perilakunya sehingga dapat memicu repeat order dan juga word-of-mouth advertisers. Penelitian ini bertujuan untuk mengetahui tingkat kepuasan pelanggan terhadap pelayanan Astra Motor Yogyakarta bagian pemasaran H1 (Penjualan). Selain itu juga ingin mengetahui apakah terdapat perbedaan yang signifikan antara tiap variabel demografi pelanggan terhadap tingkat kepuasan yang diberikan. Total responden yang diamati menggunakan tele survei yaitu sebanyak 414 pelanggan. Hasil analisis faktor konfirmatori diperoleh keputusan bahwa 5 dimensi pelayanan yang terdiri dari tangible, responsiveness, assurance, empathy, dan reliability telah valid untuk mewakili 16 indikator pertanyaan. Menggunakan metode normalisasi min-maks diperoleh hasil bahwa seluruh responden merasa puas terhadap 5 dimensi kualitas pelayanan. Kemudian hasil pengujian Kruskal Wallis diperoleh keputusan terdapat perbedaan kelompok kota, provinsi, jenis pekerjaan, dan tingkat pendapatan responden dengan tingkat kepuasan yang diberikan terhadap 5 dimensi kualitas pelayanan Astra Motor Yogyakarta bagian pemasaran H1.
\end{abstract}

Kata Kunci: Kepuasan Pelanggan, Astra Motor Yogyakarta, Analisis Faktor Konfirmatori, Normalisasi Min-Maks, Uji Kruskal Wallis.

\section{PENDAHULUAN}

Perusahaan memiliki tuntutan yang begitu kompleks akan jaminan mutu dan kualitas produk barang atau jasa. Peningkatan kualitas akan jasa yang ditawarkan semakin mendapatkan banyak perhatian bagi perusahaan. Hal ini disebabkan karena kualitas jasa dapat digunakan sebagai alat untuk mencapai keunggulan kompetitif. Masalah mengenai kualitas pelayanan, yang akan sangat berkaitan sekali dengan masalah kepuasan yang juga menyangkut tentang salah satu elemen pendukung pelayanan jasa yaitu sumber daya manusia yang ada dalam perusahaan jasa tersebut (Wijaya, 2011).

Kepuasan pelanggan dapat menjadi tolak ukur kualitas pelayanan jasa yang di berikan perusahaan tersebut. Pelanggan yang benar-benar setia terhadap produk barang/jasa akan sangat potensial memperngaruhi perilakunya sehingga dapat memicu repeat order dan juga word-of-mouth advertisers.

Dalam menghadapi tantangan ini, Bagian HC3 (Honda Customer Care Center) PT Astra International Tbk. - Honda memegang peranan dalam menangani handling komplain dari customer, serta membantu semua karyawan Honda Sales Office untuk memberikan pelayanan yang terbaik dengan memberikan informasi dan training yang berhubungan dengan pelayanan untuk meningkatkan keberhasilan proses bisnisnya. Untuk mengetahui apakah standar pelayanan yang diterapkan memberikan nilai tambah atau rasa puas kepada pelanggan, perlu diketahui terlebih dahulu karakteristik dan perilaku pelanggan. Dengan mengetahui siapa pelanggan dan bagaimana perilaku pelanggan dalam bertransaksi, PT Astra International Tbk. - Honda khususnya bagian HC3 dapat mengidentifikasi peluang yang ada dan menyusun strategi standar pelayanan yang dapat diberikan untuk menunjang penjualan produk. 


\section{Ahmad Husain Abdullah, dkk.}

Maka dari itu pendekatan statistika yang dapat diterapkan untuk mengetahui karakteristik responden yaitu analisis deskriptif dan uji kruskal wallis. Adapun rumusan masalah yang dapat disusun diantaranya: Bagaimana profil responden pada penelitian ini ; bagaimana tingkat kepuasan pelanggan atas jasa pelayanan AHM bagian $\mathrm{H} 1$ penjualan ; dan apakah terdapat perbedaan yang signifikan antar demografi terhadap tingkat kepuasan pelayanan yang diterima.

Tujuan yang hendak dicapai pada penelitian ini adalah sebagai berikut:

a) Mengetahui karakteristik profil responden pelanggan PT Astra International Tbk. - Honda pada bagian pemasaran $\mathrm{H} 1$.

b) Mengetahui tingkat kepuasan pelanggan atas jasa pelayanan PT Astra International Tbk. Honda pada bagian pemasaran $\mathrm{H} 1$.

c) Mengetahui apakah tedapat perbedaan kepuasan yang signifikan atau tidak atas pelayanan pada bagian pemasaran H1 ditinjau dari aspek usia, jenis kelamin, jenis pekerjaan, segmen kendaraan, tingkat pendidikan, dan klaster pendapatan pelanggan.

\section{METODOLOGI PENELITIAN}

\section{JENIS DAN SUMBER DATA}

Penelitian ini menggunakan data primer pada pelanggan jasa kendaraan motor Honda. Menggunakan metode survei telepon selama kurun waktu januari 2017 hingga juli 2017. Butir kuesioner terdiri atas parameter yang relevan dengan kualitas pelayanan.

\section{VARIABEL PENELITIAN}

Variabel penelitian adalah suatu hal berbentuk apa saja yang ditetapkan oleh peneliti untuk dipelajari sehingga diperoleh informasi tentang hal tersebut (Theodore, 2007). Penelitian ini terdiri atas beberapa variabel diantaranya: kepuasan pelanggan yang dirangkum dalam lima dimensi kualitas pelayanan (tangible, reliability, assurance, responsiveness, empathy), dan demografi responden (jenis kelamin, kelompok usia, pendidikan terakhir, jenis pekerjaan, pendapatan, wilayah tempat tinggal, dan segmentasi motor).

\section{UJI KUALITAS DATA}

1. Validitas

Uji validitas digunakan untuk mengetahui kelayakan butir-butir dalam pertanyaan untuk mendefinisikan suatu variabel (Umar, 2007). Setelah kuesioner akhir terbentuk, langkah selanjutnya dilakukan menguji validitas kuesioner untuk mengetahui sejauhmana suatu alat instrumen yang akan diukur. Rumus yang digunakan adalah teknik korelasi dengan metode Pearson Correlation:

$$
r=\frac{n \sum_{i=1}^{n} X_{i} Y_{i}-\sum_{i=1}^{n} X_{i} \sum_{i=1}^{n} Y_{i}}{\sqrt{\left[n \sum_{i=1}^{n} X_{i}^{2}-\left(\sum_{i=1}^{n} X_{i}^{2}\right)^{2}\right.} \sqrt{\left[n \sum_{i=1}^{n} Y_{i}^{2}-\left(\sum_{i=1}^{n} Y_{i}^{2}\right)^{2}\right.}}
$$

$$
\begin{aligned}
& \text { Keterangan : } \quad \text { rxy } \quad=\text { korelasi antar } \mathrm{X} \text { dan } \mathrm{Y} \\
& \mathrm{N} \quad=\text { jumlah responden } \\
& \mathrm{X}=\text { skor masing-masing pertanyaan } \\
& \mathrm{Y}=\text { skor total }
\end{aligned}
$$

Bukti pertanyaan kuesioner tersebut dinyatakan valid jika diperoleh hasil perhitungan rhitung $>$ rtabel pada taraf signifikan $5 \%$. 


\section{Reliabilitas}

Reliabilitas adalah alat untuk mengukur suatu kuesioner yang merupakan indikator dari variabel. Suatu kuesioner dikatakan reliabel atau handal jika jawaban seseorang terhadap pertanyaan adalah konsisten atau stabil dari waktu ke waktu (Ghozali, 2005). Dalam penguji reliabilitas menggunakan software RStudio, adapun uji reliabilitas dapat dilakukan dengan menggunakan koefisien alpha (a) dari cronbach:

$$
r_{11}=\left[\frac{K}{K-1}\right]\left[1-\frac{\sum \sigma b^{2}}{\sigma t^{2}}\right]
$$

Keterangan:

$$
\begin{array}{ll}
\mathrm{r} 11 & =\text { Reliabilitas instrumen } \\
\mathrm{K} & =\text { Banyaknya butir pertanyaan } \\
\sum \sigma b^{2} & =\text { Jumlah varians butir } \\
\sigma t^{2} & =\text { Varians total }
\end{array}
$$

Kriteria tes dikatakan reliabel jika $r_{11}>\mathrm{r}$ tabel, setelah diadakan perhitungan, maka angket tersebut valid.

\section{ANALISIS FAKTOR KONFIRMATORI}

Analisis Faktor Konfirmatori merupakan salah satu metode analisis multivariate yang dapat digunakan untuk mengkonfirmasi apakah model pengukuran yang dibangun sesuai dengan yang dihipotesiska (Efendi, 2012). Model umum analisis daktor konfirmatori menurut Primananda dalam adalah sebagai berikut:

$$
x=4 x \xi+\delta
$$

Dimana:

$x$ merupakan vektor bagi peubah-peubah indikator berukuran $\mathrm{q} \times 1$

$\Lambda x$ merupakan matriks bagi factor loading $(\lambda)$ atau koefisien yang menunjukkan hubungan $\mathrm{x}$ dengan $\xi$ berukuran q $\mathrm{x}$.

$\xi$ (ksi) merupakan vektor bagi peubah-peubah laten berukuran $\mathrm{n} \times 1$

$\delta$ vektor bagi galat pengukuran berukuran q x 1

\section{NORMALISASI MIN-MAKS}

Pada algoritma jaringan syaraf tiruan, input yang diterima berupa bilangan dengan range antara 0 sampai dengan 1. Karena itu, diperlukan sebuah proses terlebih dahulu untuk menyesuaikan data yang sesungguhnya dengan range tersebut. Proses yang digunakan adalah min-max normalization, yaitu metode normalisasi yang mentransformasi data secara linear terhadap sebuah range yang baru (Han, 2012).

$$
V^{\prime}=\frac{v-\min _{A}}{\max _{A}-\min _{A}}\left(\text { newmax }_{A}-\text { newmin }_{A}\right)+\text { newmin }_{A}
$$

\section{UJI KRUSKAL-WALLIS}

Kruskall-Wallis adalah salah satu metode statistika non-parametrik dalam kelompok untuk sampel independen. Prosedur ini digunakan untuk membandingkan dua atau lebih variabel yang diukur dengan kelompok yang tidak sama (saling bebas). Merupak uji ketika asumsi normalitas data tidak terpenuhi.

$$
H=\left[\frac{12}{n(n+1)} \sum_{j=1}^{c} \frac{T_{j}^{2}}{n_{j}}\right]-3(n+1)
$$




\section{Ahmad Husain Abdullah, dkk.}

dimana:

n : jumlah ukuran sampel

c : sampel ke-c

$T_{j} \quad$ : jumlah peringkat pada kelompok ke-j

$n_{j} \quad$ : jumlah sampel pada kelompok ke-i

\section{TAHAPAN ANALISIS}

Adapun tahapan pada penelitian ini adalah sebagai berikut:

1. Analisis deskriptif untuk melihat karakteristik responden yang diamati.

2. Melakukan analisis faktor konfirmatori untuk menguji tingkat validasi faktor dimensi kualitas pelayanan yang dibentuk.

3. Pengujian kualitas data dengan uji validitas dan reliabilitas.

4. Normalisasi min-maks untuk melihat tingkat kepuasan pelanggan.

5. Analisis kruskal wallis untuk melihat perbedaan antara kelompok demografi responden dengan kepuasan pelayanan yang diterima.

\section{HASIL DAN PEMBAHASAN}

\section{ANALISIS DESKRIPTIF}

Data demografi responden diolah menggunakan program Rstudio untuk mengetahui gambaran umum atau karakteristik dari seluruh responden pada penelitian ini.
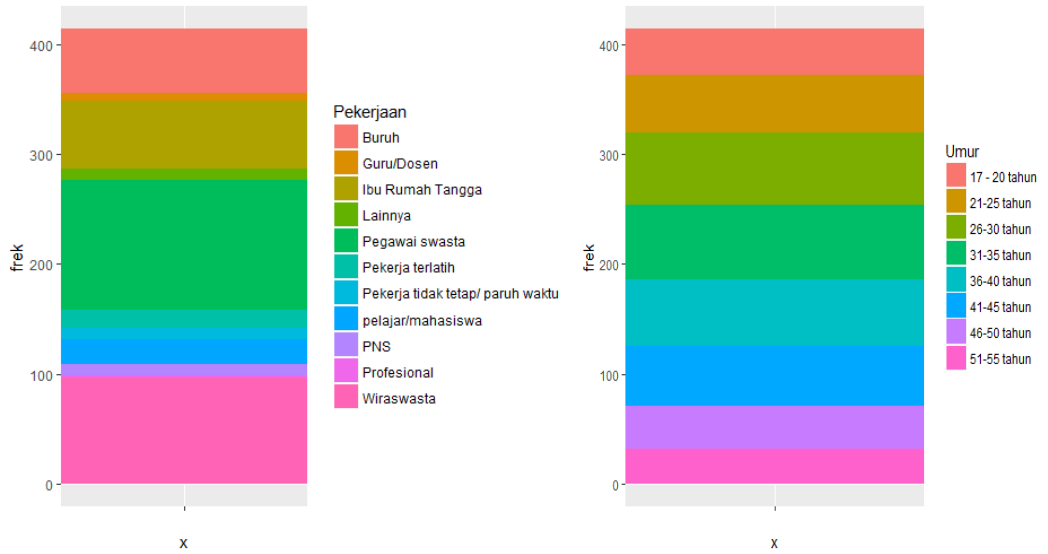

Gambar 2. Grafik Jenis Pekerjaan dan Kelompok Umur.
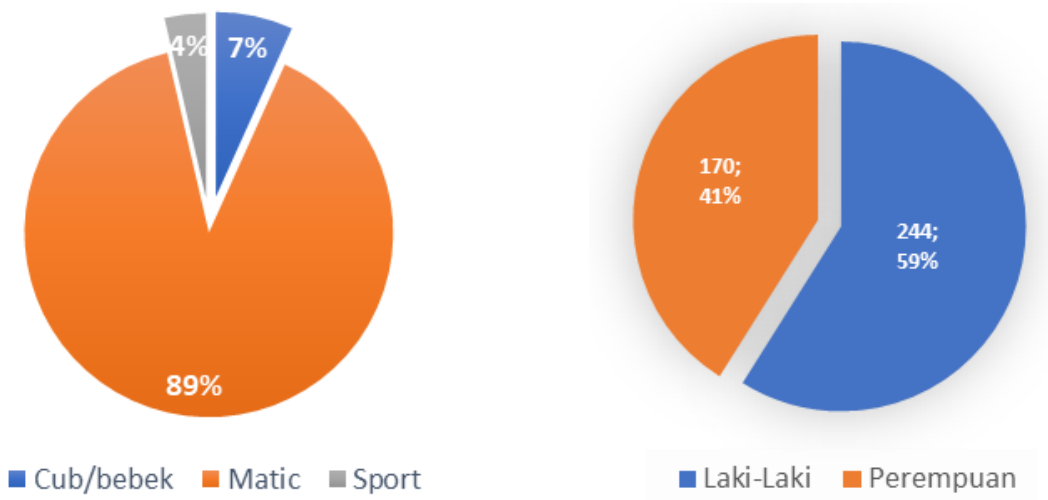

Gambar 2. Grafik Jenis Kelamin dan Segmen Kendaraan. 

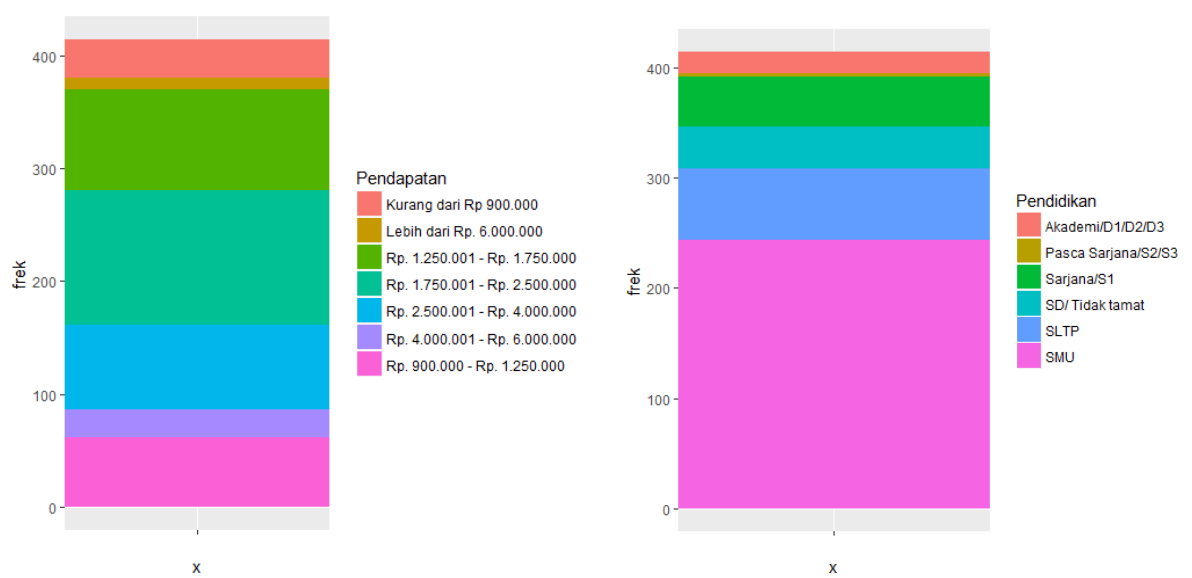

Gambar 3. Grafik Kelompok Pendapatan dan Tingkan Pendidikan.

Berdasarkan hasil perhitungan diperoleh informasi 58,9\% dari responden adalah laki-laki dan sisanya perempuan. Kemudian jika ditinjau dari kelompok usia di dominasi oleh kelompok usia 31 - 35 tahun dengan proporsi 16,4\% diikuti dengan kelompok usia 26-30 tahun yakni 15,9\%. Berarti segmen usia yang mendominasi pelanggan motor honda pada penelitian ini yaitu usia muda. Selain itu, dari tingkat pendidikan, sebagian besar responden mengenyam pendidikan terakhir SMU dengan persentase 58,9\%. Lalu, dari sektor jenis pekerjaan yang paling tinggi rasionya adalah pegawai swasta dengan persentase $28,5 \%$ sedangkan yang paling rendah yakni profesional (dokter, notaris) dengan persentase 0,5\% dari seluruh responden. Ditilik dari pendapatan perbulan, sebagian besar responden berada pada kelompok Rp 1.750 .000 hingga Rp 2.500.000 dengan proporsi sebesar 28,7\%. Kemudian dari segmen kendaraan motor honda yang paling dominan yaitu jenis matic dengan persentase $89,6 \%$ diikuti bebek/cub dan sport yang masing-masing sebesar $6,8 \%$ dan $3,6 \%$.

\section{ANALISIS FAKTOR KONFIRMATORI}

Pada tahap pengujian validasi dari faktor yang terbentuk dapat menggunakan nilai Kaiser Mayer Olkin (KMO) (Putri, 2013).

Tabel 1. Ringkasan Hasil Analisis Faktor Konfirmatori.

\begin{tabular}{lcc}
\hline Variabel & KMO & Keterangan \\
\hline Tangible & 0,83 & Valid \\
Responsiveness & 0,87 & Valid \\
Assurance & 0,86 & Valid \\
Empathy & 0,93 & Valid \\
Reliability & 0,86 & Valid
\end{tabular}

Faktor yang terbentuk dikatakan baik jika nilai KMO lebih dari 0,6 (Putri, 2013). Maka berdasarkan tabel 1 seluruh faktor dinyatakan valid.

\section{PENGUJIAN KUALITAS DATA}

1. Uji Validitas

Pada penelitian kali ini peneliti menggunakan data sebanyak 414 responden, artinya $\mathrm{N}=414$; df

$=\mathrm{N}-2$, maka df $=412$, dilihat dari data di peroleh tabel sebesar 1,9657. Selanjutnya ialah mencari nilai $\mathrm{r}_{\text {tabel }}$ dengan perhitungan sebagai berikut: 
118 Ahmad Husain Abdullah, dkk.

$r_{\text {tabel }}=\frac{1,9657}{\sqrt{412+1,9657^{2}}}=0,162$

Kemudian dengan menggunakan pendekatan rumus Pearson Correlation (1) diperoleh ringkasan hasil seperti tabel berikut:

Tabel 2. Uji Validitas Data.

\begin{tabular}{lcccc}
\hline Variabel & Indikator Pertanyaan & $\mathbf{r}_{\mathbf{x y}}$ & $\mathbf{r}_{\text {tabel }}$ & Keterangan \\
\hline \multirow{3}{*}{ Tangible } & A1 & 0,766 & 0,162 & Valid \\
& A3 & 0,692 & 0,162 & Valid \\
& A4 & 0,687 & 0,162 & Valid \\
& G21 & 0,771 & 0,162 & Valid \\
Assurance & G22 & 0,777 & 0,162 & Valid \\
\hline \multirow{2}{*}{ Responsiveness } & B6 & 0,726 & 0,162 & Valid \\
& B7 & 0,749 & 0,162 & Valid \\
& B10 & 0,736 & 0,162 & Valid \\
Reliability & G23 & 0,735 & 0,162 & Valid \\
\hline \multirow{2}{*}{ Empathy } & H29 & 0,754 & 0,162 & Valid \\
& G19 & 0,711 & 0,162 & Valid \\
\hline G20 & 0,731 & 0,162 & Valid \\
& H27 & 0,804 & 0,162 & Valid \\
& I30 & 0,658 & 0,162 & Valid \\
\hline
\end{tabular}

Karena nilai hasil seluruh butir pertanyaan memiliki $r_{\text {hitung }}>r_{\text {tabel }}$ maka instrumen pernyataan tersebut dinyatakan valid.

2. Uji Reliabilitas

Kemudian melakukan uji reliabilitas dengan perintah 'cronbach' pada progra Rstudio diperoleh nilai Cronbach's alpha sebesar 0,943. Karena hasil nilai Cronbach's alpha $(0,943)>0,7$ maka seluruh item variabel handal dan seluruh tes secara konsisten memiliki reliabilitas yang kuat.

\section{NORMALISASI MIN-MAKS}

Ketika telah mendapatkan hasil skor butir pernyataan pada setiap faktor yang terbentuk, tahap selanjutnya yaitu mentransformasikan kedalam range baru dengan metode min-max normalization. Pada penelitian ini penulis menggunakan 0 hingga 1 untuk mengukur kepuasan pelanggan. Berikut ini merupakan contoh simulasi perhitungannya pada responden yang pertama terhadap penliaian variabel bukti fisik (tangible):

$$
\text { value }^{\prime}=\frac{22-5}{25-5}(1-0)+0=0,85
$$

Angka 22 merupakah hasil kalkulasi respon dari pelanggan terhadap variabel tangible yang mencakup 5 indikator pernyataan didalamnya. Angka 4 adalah original min yang diperoleh dari nilai terendah nilai skor skala likert 1 hingga 5 (persepsi skor kepuasan pelanggan) kemudian dikalikan dengan jumlah butir pertanyaan sesuai dengan jumlah indikator yang ada yaitu 5 sehingga nilai original min 1 x $5=5$. Angka 25 merupakan original max yang diperoleh dari nilai tertinggi pada nilai skor skala likert 1 hingga 5 (persepsi skor kepuasan pelanggan) kemudian 
dikalikan dengan jumlah butir pertanyaan sesuai dengan jumlah indikator yang ada yaitu 5 sehingga nilai original max $5 \times 5=25$. Angka 1 menunjukkan nilai newmax sedangkan angka 0 menunjukkan nilai newmin, penulis memilih angka 1 dan 0 untuk mentransformasikan data agar data setelah ditransformasikan ada maknanya, jika data transformasi menunjukkan angka 1 artinya bahwa sangat puas jika data transformasi menunjukkan angka 0 artinya bahwa sangat tidak puas.

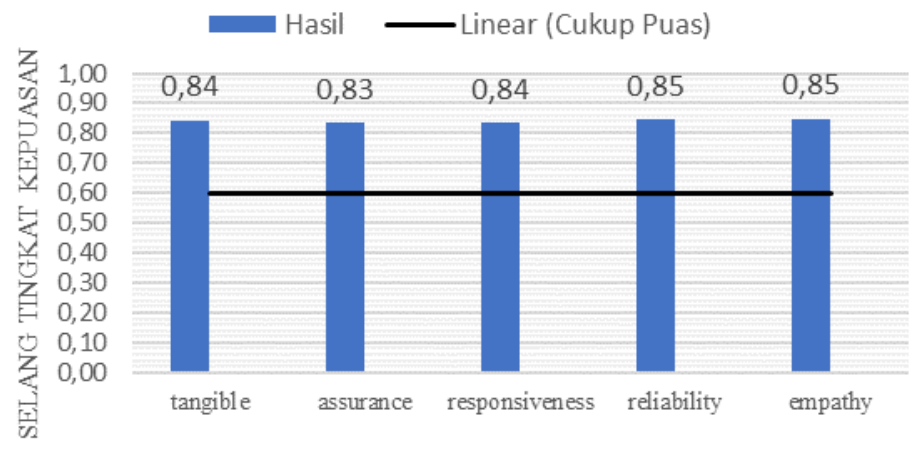

DIMENSI PELAYANAN

Gambar 4. Diagram Batang Tingkat Kepuasan Pelanggan

Berdasarkan gambar 4.4 seluruh variabel dimensi pelayanan berada diatas garis linear cukup puas. Sehingga dapat dikatakan 414 pelanggan pada bagian pemasaran H1 (Penjualan) di Astra Honda Motor memberikan respon sangat puas terhadap 5 dimensi kualitas pelayanan yang diberikan.

\section{UJI KRUSKALL-WALLIS}

Sebelumnya, pengujian normalitas data dilakukan pada seluruh dimensi kualitas pelayanan. Namun hasilnya 5 dimensi tersebut tidak lolos uji normalitas. Sehingga pembuktian hipotesis dalam penelitian kali ini dilakukan dengan metode analisis Kruskal Wallis. Uji Kruskal Wallis untuk mengetahui ada tidaknya perbedaan kelompok pada tiap variabel demografi terhadap tingkat kepuasan 5 dimensi pelayanan pada Astra Honda Motor bagian pemasaran H1 (Penjualan).

Tabel 3. Hasil Perhitungan Uji Kruskal Wallis.

\begin{tabular}{lcrrc}
\hline \multicolumn{1}{c}{ Faktor } & df & Chi-Square & P-Value & Keputusan \\
\hline Jenis Kelamin & 1 & 1,5617 & 0,21 & Gagal Tolak Ho \\
Kelompok Umur & 7 & 4,3625 & 0,732 & Gagal Tolak Ho \\
Kota & 10 & 98,151 & 0,000 & Tolak Ho \\
Provinsi & 1 & 19,378 & 0,000 & Tolak Ho \\
Segmen Kendaraan & 2 & 1,9251 & 0,389 & Gagal Tolak Ho \\
Tingkat Pendidikan & 5 & 6,578 & 0,254 & Gagal Tolak Ho \\
Pendapatan & 7 & 14,946 & 0,036 & Tolak Ho \\
Jenis Pekerjaan & 10 & 23,042 & 0,01 & Tolak Ho
\end{tabular}

Hasil pengujian pada tabel 3 menunjukkan bahwa variabel demografi responden yang meliputi kota, provinsi, pendapatan, dan jenis pekerjaan mempunya perbedaan yang signifikan 
120 Ahmad Husain Abdullah, dkk.

terhadap persepsi pelanggan dalam memberikan respon kepuasan 5 dimensi pelayanan di Astra Honda Motor bagian pemasaran H1 (Penjualan). Simpulan tersebut diperoleh karena nilai signifikansi p-value tiap variabel tersebut $(0,000)<\mathrm{a}(0,05)$.

Perbedaan yang nyata antara kelompok provinsi dan tingkat kepuasan serta perbedaan antara kelompok kota asal responden dengan tingkat kepuasan yang diberikan sesuai dengan teori sosiokultural. Bahwasannya karakteristik tiap penduduk dalam berkehidupan cenderung memiliki hubungan yang erat dengan lingkungan fisiknya (Bambang, 2008).

Maka dari itu ketika kajian teoritis terkait perbedaan karakter tiap wilayah telah terbuktikan dengan perhitungan hipotesis, pihak HSO Yogyakarta perlu mengambil langkah strategis. Langkah yang dibutuhkan untuk meningkatkan kesadaran SDM (Sales Person) yang dimilikinya agar mampu mehami kepribadian maupun watak berdasarkan letak wilayah asalnya. Pemahaman tersebut nantinya diterapkan ketika melayani pelanggan. Dengan demikian kepuasan pelanggan terhadap 5 dimensi kualitas pelayanan yang diberikan dapat meningkat.

Kemudian keputusan hipotesis bahwa terdapat perbedaan antara kelompok tingkat pendapatan dan jenis pekerjaan responden dengan tingkat kepuasan yang diberikan selaras dengan simpulan penelitian yang dilakukan oleh Vinota pada tahun 2017 yang mengkaji kepuasan pelanggan juga (Vinotha, 2017). Oleh karenanya, HSO Yogyakarta melalui bagian HC3 ketika melakukan pelatihan kepada Front Line People dapat menghimbau hasil tersebut. Sehingga dalam pelaksanaannya baik itu sales person ataupun greeter dapat memahami pelayanan yang harus diberikan sesuai dengan karakter pelanggan masing-masing.

\section{KESIMPULAN}

Dari penelitian yang berjudul "Analisis Kepuasan Pelanggan Terhadap Pelayanan Astra Motor Yogyakarta Bagian H1 Penjualan Unit Sepeda Motor" dapat ditarik beberapa simpulan sesuai dengan masalah yang dirumuskan, yakni antara lain:

1. Hasil olah statistika deskriptif profil responden diperoleh informasi 58,9\% dari responden adalah laki-laki dan sisanya perempuan. Kemudian jika ditinjau dari kelompok usia di dominasi oleh kelompok usia 31 - 35 tahun dengan proporsi 16,4\%. Sebagian besar responden mengenyam pendidikan terakhir SMU dengan persentase 58,9\%. Sektor jenis pekerjaan yang paling tinggi rasionya adalah pegawai swasta dengan persentase $28,5 \%$. Ditilik dari pendapatan perbulan, sebagian besar responden berada pada kelompok Rp 1.750.000 hingga Rp 2.500.000 dengan proporsi sebesar 28,7\%. Kemudian dari segmen kendaraan motor honda yang paling dominan yaitu jenis matic dengan persentase 89,6\%.

2. Seluruh variabel dimensi pelayanan (tangible, responsiveness, empathy, assurance, reliability) berada diatas garis linear cukup puas. Sehingga dapat dikatakan 414 responden pelanggan pada bagian pemasaran H1 (Penjualan) di Astra Honda Motor memberikan respon sangat puas terhadap 5 dimensi kualitas pelayanan yang diberikan.

3. Menggunakan pendekatan Uji Kruskal-Wallis dengan tingkat signifikansi 5\% diperoleh keputusan terdapat perbedaan nyata kelompok pendapatan, pekerjaan, kota, dan provinsi responden terhadap tingkat kepuasan yang diberikan.

\section{DAFTAR PUSTAKA}

Wijaya, T. (2011). Manajemen Pemasaran dan Pemasaran Jasa. Bandung: Alfabeta.

Theodore, B. (2007). Analisis Kepuasan Konsumen Terhadap Jasa Internet Kabel Pada PT Jogja Medianet. Yogyakarta: Skripsi Fakultas Ekonomi Universitas Sanata Dharma.

Umar, H. (2007). Metode Penelitian Untuk Sripsi dan Tesis Bisnis. Jakarta: PT. Raja Grafindo Persada.

Ghozali, I. (2005). Model Persamaan Struktural: Konsep dan Aplikasi dengan Program AMOS Ver. 5.0. Semarang: Badan Penerbit Universitas Diponegoro Semarang.

Efendi, M. M., \& Purnomo, J. D. (2012, September). Analisis Faktor Konfirmatori untuk Mengetahui Kesadaran Berlalu Lintas Pengendara Sepeda Motor di Surabaya Timur. Jurnal Sains dan Seni ITS, I, 106-111.

Statistika, Vol. 18, No. 2, November 2018 
Han, J., Kamber, M., \& Pei, J. (2012). Data Mining: concept and Technique 3rd Edition. Waltham USA: Morgan Kaufmann Publisher.

Putri, K. I., \& Nurcahya, I. N. (2013, Juli 8). Pengaruh Dimensi Kualitas Pelayanan Jasa Terhadap Kepuasan Pelanggan D\&I Skin Centre Denpasar. Jurnal Manajemen Universitas Udayana, II(2), 918-937.

Bambang, S. H. (2008). Diktat Kuliah : Geografi Regional Indonesia. Yogyakarta: Universitas Negeri Yogyakarta.

Vinotha. (2017). Customer Satisfaction on Honda Activa A Special Reference with North Chennai. International Journal of Science and Research , $2270-2273$.

\section{LAMPIRAN}

Lampiran 1. Indikator Pertanyaan Kuesioner.

\begin{tabular}{|c|c|}
\hline Indikator & Keterangan \\
\hline A1 & $\begin{array}{l}\text { Kemudahan dalam menemukan dan menghubungi showroom/dealer resmi } \\
\text { Honda (lokasi, telepon, jam kerja) }\end{array}$ \\
\hline A3 & Kebersihan dan kerapian di dalam showroom/dealer resmi Honda \\
\hline A4 & Ketersediaan informasi produk (brosur, daftar harga, leaflet, spanduk) \\
\hline G2 1 & Kelengkapan dan kebersihan sepeda motor yang dikirim \\
\hline G22 & $\begin{array}{l}\text { Kualitas sepeda motor pada saat diterima oleh konsumen (tidak lecet, tidak } \\
\text { berkarat, dll) }\end{array}$ \\
\hline B6 & $\begin{array}{l}\text { Kemampuan petugas penjualan (sales counter) dalam menjelaskan spesifikasi } \\
\text { produk dan menyarankan produk yang sesuai dengan kebutuhan konsumen }\end{array}$ \\
\hline B7 & $\begin{array}{l}\text { Penjelasan petugas penjualan (sales counter) mengenai bentuk serta paket } \\
\text { pembayaran sepeda motor (tunai/kredit, tempat pembayaran) }\end{array}$ \\
\hline B10 & $\begin{array}{l}\text { Penjelasan petugas pada saat penyerahan motor mengenai bengkel resmi Honda } \\
\text { (AHASS) terdekat, jadwal servis sepeda motor, serta garansi pembelian }\end{array}$ \\
\hline G23 & $\begin{array}{l}\text { Kemampuan petugas pengiriman dalam menjelaskan dan memperagakan fungsi } \\
\text { fitur sepeda motor,garansi motor (kelistrikan, mesin dan rangka), buku servis } \\
\text { berkala dan buku pedoman perawatan motor. }\end{array}$ \\
\hline F18 & $\begin{array}{l}\text { Kecekatan petugas kasir dalam melayani pembayaran tunai, kredit, atau uang } \\
\text { muka. }\end{array}$ \\
\hline $\mathrm{H} 29$ & Kemudahan dalam proses pengambilan STNK \\
\hline G19 & Ketepatan waktu pengiriman/penyerahan sepeda motor sesuai yang dijanjikan \\
\hline G20 & $\begin{array}{l}\text { Kesesuaian antara pesanan dengan sepeda motor yang dikirim baik dari tipe dan } \\
\text { warnanya }\end{array}$ \\
\hline $\mathrm{H} 27$ & Ketepatan waktu penyerahan STNK sesuai yang dijanjikan \\
\hline I30 & $\begin{array}{l}\text { Keramahan dan kesopanan (senyum, salam, sapa, sopan, santun) petugas dealer } \\
\text { baik salesman/SPG, kasir, dan petugas pengiriman. }\end{array}$ \\
\hline I31 & $\begin{array}{l}\text { Penampilan (kerapian, kebersihan seragam) petugas dealer baik salesman/SPG, } \\
\text { kasir, dan petugas pengiriman. }\end{array}$ \\
\hline
\end{tabular}
kasir, dan petugas pengiriman. 